\title{
Contrast-Induced Nephropathy in Patients with Hepatocellular Carcinoma Undergoing Transcatheter Arterial Chemoembolization
}

\author{
Ryusuke Murakami, Hidemasa Saito, Izumi Miki, Daisuke Yasui, Fumie Sugihara, \\ Tatsuo Ueda, Satoru Murata, Hiromitsu Hayashi, Shinichiro Kumita \\ Department of Radiology, Nippon Medical School, Tokyo, Japan \\ Email: rywakana@nms.ac.jp
}

Received 19 August 2016; accepted 19 September 2016; published 22 September 2016

Copyright (C) 2016 by authors and Scientific Research Publishing Inc.

This work is licensed under the Creative Commons Attribution International License (CC BY).

http://creativecommons.org/licenses/by/4.0/

(c) (i) Open Access

\begin{abstract}
Purpose: The purpose of this retrospective study was to assess the incidence and the risk factors of contrast-induced nephropathy (CIN) following transcatheter arterial chemoembolization (TACE) in patients with hepatocellular carcinoma (HCC). Materials and Methods: We performed a retrospective review of 186 sessions of TACE in 122 patients with HCC. We examined the incidence and factors associated with risk of CIN, defined as an increase of at least $0.5 \mathrm{mg} / \mathrm{dl}(44.2 \mu \mathrm{mol} / \mathrm{l})$ or $25 \%$ of the baseline serum creatinine level between 48 and 72 hours after TACE. Results: CIN developed in $14(7.5 \%)$ of the 186 sessions after TACE. A univariate analysis showed that the ChildPugh class $B$ or $C[10 / 14(71 \%)$ vs. $70 / 172(41 \%), P=0.046]$, a low albumin level $(3.0 \pm 0.5$ vs. $3.4 \pm$ $0.6, P=0.018)$, and a low hemoglobin level $(10.6 \pm 2.0$ vs. $11.8 \pm 2.0, P=0.035)$ were significantly associated with the development of CIN. Multivariate analysis revealed that the hemoglobin value was associated with CIN [odds ratio (OR) 1.6; $P=0.038$ ]. Conclusions: CIN after TACE is closely associated with the severity of liver cirrhosis, and with low levels of albumin and hemoglobin. Effective preventive methods remain to be considered in patients with HCC and advanced LC who are undergoing TACE.
\end{abstract}

\section{Keywords}

Contrast Induced Nephropathy, Hepatocellular Carcinoma, Transcatheter Arterial Chemoembolization, Contrast Media

\section{Introduction}

Hepatocellular carcinoma (HCC) is one of the most common malignant diseases in the world, and its incidence

How to cite this paper: Murakami, R., Saito, H., Miki, I., Yasui, D., Sugihara, F., Ueda, T., Murata, S., Hayashi, H. and Kumita, S. (2016) Contrast-Induced Nephropathy in Patients with Hepatocellular Carcinoma Undergoing Transcatheter Arterial Chemoembolization. Open Journal of Radiology, 6, 243-249. http://dx.doi.org/10.4236/ojrad.2016.63032 
is currently increasing. In developed countries, HCC is diagnosed at an early stage in $30 \%$ - $40 \%$ of all patients, when it is amenable to treatment such as surgical resection, liver transplantation and local ablative treatments [1] [2]. To date, no systemic therapy has been developed that improves the survival of patients with advanced HCC [3]. Transcatheter arterial chemoembolization (TACE) has been recognized as an effective palliative treatment option for patients in whom surgical or local ablative treatment is contraindicated; it currently plays a major role in treating advanced HCC [4] [5].

Patients with HCC frequently have advanced liver cirrhosis (LC), which in advanced cases is characterized by peripheral vasodilatation associated with decreased renal perfusion due to activation of the vasoconstrictor system [6] [7]. Therefore, LC may be a predisposing factor for declining renal function.

Contrast-induced nephropathy (CIN) is the third leading cause of hospital-acquired acute renal failure (ARF), accounting for $10 \%$ of all cases, and contributes to prolonged hospitalization and increased medical costs [8] [9]. Important risk factors for CIN include pre-existing renal insufficiency, particularly that caused by diabetic nephropathy, reduced circulating volume, the volume and type of contrast medium (CM) employed, and concomitant administration of potentially nephrotoxic drugs [10]-[12].

Despite the high clinical importance of renal insufficiency in HCC patient post-TACE, few reported studies have assessed the risk of CIN and TACE [13]-[15]. Several risk factors such as preoperative serum albumin, proteinuria level, coexisting hypertension (HT) and diabetes (DM), grade of LC, treatment session, and the amount and types of CM used in TACE have been suspected the association with the development of CIN. The risk factors developing CIN in HCC patient post-TACE have been still limited and remain unclear. Additional studies are therefore necessary to assess the clinical aspects of CIN occurrence after TACE. Here, we investigated the incidence and risk factors for CIN in patients with HCC who were undergoing TACE.

\section{Materials and Methods}

\subsection{Patients}

The institutional review board approved this retrospective study and written informed consent was obtained from each patient before the TACE procedure. Between 1 January 2012 and 31 December 2012, we retrospectively reviewed the medical records of 130 patients with HCC who had undergone TACE. We excluded patients with acute or chronic renal failure undergoing renal replacement therapy such as hemodialysis or peritoneal dialysis (4 patients) before the TACE procedure, and patients who died within a week after the TACE procedure because of gastrointestinal bleeding ( 2 patients), liver failure (1 patient), and cerebral hemorrhage (1 patient). The diagnosis of HCC was confirmed histologically by needle biopsy or based on the findings of typical radiological features in at least two imaging examinations including ultrasonography, contrast-enhanced dynamic computed tomography, and magnetic resonance imaging.

\subsection{TACE Procedure}

TACE was performed according to Seldinger's technique of arterial embolization. The femoral artery was punctured, and hepatic arteriography and superior mesenteric arterial portovenography were performed to define the size and location of the tumor nodules. A non-ionic low-osmolality CM, iopamidol (Iopamiron 300, Bayer, Tokyo, Japan), iohexol (Omnipaque 300, Daiichi-Sankyo, Tokyo, Japan) or iomeprol (Iomeron 300, Eizai, Tokyo, Japan), was used. The arteries supplying the tumor were super-selectively catheterized and the catheter position was controlled according to the tumor distribution and anatomical variations. The prepared oil emulsion was then slowly injected and the feeding arteries were completely embolized with gelatin sponge particles (Gelpart; Nippon Kayaku, Tokyo, Japan) that had been crushed to approximately $0.2-0.5 \mathrm{~mm}$ soaked in $10 \mathrm{~mL}$ of the CM. This was achieved by pumping using a three-way stopcock valve and two 2.5-mL syringes. The oil emulsions were prepared by mixing 2 - $10 \mathrm{~mL}$ of iodized oil and 10 - $50 \mathrm{mg}$ epirubicin (Farmorbicin; Pfizer, Tokyo, Japan), 20 - 140 mg miriplatin hydrate (Miripla; Dainippon Sumitomo Pharma, Osaka, Japan) or 10 $100 \mathrm{mg}$ cisplatin (DDPH, IA-call; Nippon Kayaku, Tokyo, Japan). TACE was terminated when the tumorfeeding branch had become completely occluded and the tumor stain had disappeared on DSA.

Patients with an estimated glomerular filtration rate (eGFR) $<45 \mathrm{~mL} / \mathrm{min} / 1.73 \mathrm{~m}^{2}$ were used saline hydration $1000 \mathrm{~mL}$ prior to and after TACE procedure. No other CIN preventive strategies were used. 


\subsection{Data Analysis}

Blood samples for determination of serum creatinine (SCr), albumin, total bilirubin, aspartate aminotransferase (AST), alanine aminotransferase (ALT), prothrombin time, hemoglobin, platelet count, HBsAg, HCVAb, alpha fetoprotein (AFP), protein induced by vitamin $\mathrm{K}$ absence or antagonist-II (PIVKA-II) were obtained within 48 hours before the examination. The evaluation of hepatic functional reserve was based on the Child-Pugh classification. Also at 48 - 72 hours after administration of CM, SCr was determined again. Renal function was also assessed by the eGFR using the Modification of Diet in Renal Disease (MDRD) study equation, and eGFR was expressed as $\mathrm{mL} / \mathrm{min} / 1.73 \mathrm{~m}^{2}$.

CIN was defined as an increase in the serum creatinine concentration (SCr) of $\geq 0.5 \mathrm{mg} / \mathrm{dl}$ ( $44.2 \mu \mathrm{mol} / \mathrm{l}$ ), or $\geq 25 \%$ from the baseline between 48 and $72 \mathrm{~h}$ after TACE. Patients in which CIN occurred and did not occur after TACE were defined as the CIN group and the non-CIN group, respectively.

\subsection{Statistical Analysis}

Statistical testing was performed at a significance level of $\mathrm{P}<0.05$ with $95 \%$ confidence limits. Categorical variables, such as the incidence of CIN, were analyzed by the chi-squared and Fisher's exact tests. Comparisons of continuous variables were analyzed using the nonparametric Mann-Whitney test. A multivariate logistic regression model, which included potential risk factors such as age, DM, CM volume, Child-Pugh classification, and initial eGFR, was applied. A P value $<0.05$ was considered to indicate statistical significance. Analyses were performed with the SPSS statistical software package version 20.0 (SPSS, Inc., Chicago, IL, USA).

\section{Results}

\subsection{Clinical and Biochemical Characteristics}

In total, 130 patients with HCC underwent TACE during the study period, of whom 122 were included in this study. A total of 186 TACE sessions were conducted. The clinical and biochemical baseline characteristics of the patients are shown in Table 1. The mean age was $72.5 \pm 8.0$ years. Complications included HT in 75 patients (40\%) and DM in 65 (35\%). The mean eGFR was $68.8 \pm 19.4 \mathrm{~mL} / \mathrm{min}$, and 73 patients (39\%) had an eGFR of $<60 \mathrm{~mL} / \mathrm{min}$. The average total volume of CM used during TACE was $148 \pm 45 \mathrm{~mL}$.

\subsection{Incidence and Risk Factors for CIN after TACE}

CIN developed after 14 (7.5\%) of the 186 TACE sessions. No patients required dialysis after the TACE procedure, and no patients died due to ARF. The baseline characteristics of the CIN group and the non-CIN group are shown in Table 2. In the CIN group, the levels of serum albumin ( $3.0 \pm 0.5$ vs. $3.4 \pm 0.6, \mathrm{P}=0.018)$ and hemoglobin (10.6 \pm 2.0 vs. $11.8 \pm 2.0, \mathrm{P}=0.035)$ were significantly lower than in the non-CIN group. Child-Pugh class $\mathrm{B}$ or $\mathrm{C}$ was significantly associated with the development of CIN [10/14 (71\%) vs. 70/172 (41\%) $\mathrm{P}=$ 0.046]. No inter-group difference was observed in gender, age, the number of patients with HT or DM, previous TACE sessions, or the volume of CM. Basal SCr levels and eGFR also showed no significant inter-group differences. Five sessions (36\%) in the CIN group and 68 (40\%) in the non-CIN group were associated with GFRs of $<60 \mathrm{~mL} / \mathrm{min}(\mathrm{P}=0.778)$.

Table 1. Baseline clinical characteristics of the 186 treatment sessions.

\begin{tabular}{cc} 
Male/Female & $136 / 50$ \\
Age (Years) & $72.5 \pm 8.0$ \\
HT (\%) & $75(40 \%)$ \\
DM (\%) & $65(35 \%)$ \\
SCr $(\mathrm{mg} / \mathrm{dl})$ & $6.83 \pm 0.21$ \\
eGFR $\left(\mathrm{mL} / \mathrm{min} / 1.73 \mathrm{~m}^{2}\right)$ & $68.8 \pm 19.4$ \\
eGFR $<60 \mathrm{~mL} / \mathrm{min}(\%)$ & $73(39 \%)$ \\
\hline
\end{tabular}


Table 2. Comparison of patients with and without CIN after TACE.

\begin{tabular}{|c|c|c|c|}
\hline & CIN $(n=14)$ & No CIN $(n=172)$ & $\mathrm{P}$ \\
\hline Male/Female & $12 / 2$ & $124 / 48$ & 0.3587 \\
\hline Age (Years) & $70.8 \pm 6.2$ & $72.6 \pm 8.2$ & 0.4837 \\
\hline HT (\%) & $5(36 \%)$ & $70(41 \%)$ & 0.7147 \\
\hline DM (\%) & $5(36 \%)$ & $60(35 \%)$ & 0.8190 \\
\hline $\mathrm{SCr}(\mathrm{mg} / \mathrm{dl})$ & $0.80 \pm 0.22$ & $0.84 \pm 0.22$ & 0.7745 \\
\hline eGFR $\left(\mathrm{mL} / \mathrm{min} / 1.73 \mathrm{~mm}^{2}\right)$ & $76.2 \pm 23.7$ & $68.4 \pm 19.0$ & 0.5561 \\
\hline $\mathrm{eGFR}<60 \mathrm{~mL} / \mathrm{min}(\%)$ & $5(36 \%)$ & $68(40 \%)$ & 0.7783 \\
\hline Previous TACE sessions & $3.4 \pm 3.0$ & $2.5 \pm 2.6$ & 0.3461 \\
\hline Multiple HCC (\%) & $10(71 \%)$ & 117 (68\%) & 0.9718 \\
\hline Diameter max HCC (mm) & $37.0 \pm 35.8$ & $28.4 \pm 18.8$ & 0.2895 \\
\hline Contrast volume (mL) & $154 \pm 43$ & $147 \pm 45$ & 0.4671 \\
\hline Chemotherapy & & & 0.1668 \\
\hline Miriplatin & 3 & 75 & \\
\hline Cisplatin & 11 & 78 & \\
\hline Epirubisin & 2 & 19 & \\
\hline Child-Pugh class B or C & $10(71 \%)$ & $70(41 \%)$ & $0.0459^{*}$ \\
\hline Ascites & $2(14 \%)$ & $29(17 \%)$ & 0.5883 \\
\hline HBsAg-positive & $3(21 \%)$ & $15(8.7 \%)$ & 0.2817 \\
\hline HCVAb-positive & $9(64 \%)$ & $121(70 \%)$ & 0.8629 \\
\hline Albumin (g/dl) & $3.0 \pm 0.5$ & $3.4 \pm 0.6$ & $0.0175^{*}$ \\
\hline Total bilirubin (mg/dl) & $1.0 \pm 0.5$ & $0.9 \pm 0.5$ & 0.1940 \\
\hline AST (mg/dl) & $70.8 \pm 54.0$ & $59.7 \pm 40.4$ & 0.6739 \\
\hline $\operatorname{ALT}(\mathrm{mg} / \mathrm{dl})$ & $50.7 \pm 45.2$ & $47.3 \pm 42.0$ & 0.7391 \\
\hline Prothrombin time (INR) & $1.16 \pm 0.31$ & $1.22 \pm 0.81$ & 0.2794 \\
\hline Platelet count & $11.7 \pm 6.2$ & $11.8 \pm 5.4$ & 0.7725 \\
\hline Hemoglobin & $10.6 \pm 2.0$ & $11.8 \pm 2.0$ & $0.0351^{*}$ \\
\hline AFP (ng/mL) & $1105 \pm 3132$ & $842 \pm 2074$ & 0.6029 \\
\hline PIVKA-II (IU/mL) & $249 \pm 455$ & $1854 \pm 6688$ & 0.1969 \\
\hline
\end{tabular}

After adjustment for age, Child-Pugh class B or C, DM, volume of CM, baseline eGFR, albumin and hemoglobin, multivariate analysis revealed that only the hemoglobin level had a statistically significant effect on the occurrence of CIN after TACE [odds ratio (OR) 1.57; 95\% confidence interval (CI) $1.026-2.400, \mathrm{P}=0.0375$ ] (Table 3).

\section{Discussion}

The major finding of our study was that the incidence of CIN after TACE with HCC patients was $7.5 \%$. This number is slightly different from the numbers in other study reports. One of the reasons is considered likely due to differences in the different criteria in the diagnosis of CIN. One study reported that the incidence of CIN in 
Table 3. Independent risk factors associated with CIN occurrence.

\begin{tabular}{cccc}
\hline Variables & $\mathrm{P}$ & OR & 95\% Confidence interval \\
\hline Age & 0.9025 & 0.99 & $0.917-1.079$ \\
Sex & 0.1514 & 0.29 & $0.052-1.579$ \\
eGFR & 0.2534 & 0.98 & $0.946-1.015$ \\
Contrast volume & 0.4106 & 0.99 & $0.983-1.008$ \\
HT & 0.2804 & 0.47 & $0.121-1.846$ \\
DM & 0.8240 & 0.86 & $0.235-3.164$ \\
Child-Pugh class B or C & 0.1751 & 0.34 & $0.071-1.618$ \\
Albumin & 0.9974 & 1.00 & $0.227-4.436$ \\
Hemoglobin & $0.0375^{*}$ & 1.57 & $1.026-2.400$ \\
\hline
\end{tabular}

843 patients undergoing TACE was $6.6 \%$ [13], the definition of CIN being an abrupt increase of $\geq 50 \%$ over the baseline, or an absolute increase of $\geq 0.5 \mathrm{mg} / \mathrm{dl}$, in the serum creatinine level. Another study reported that the incidence of CIN in 236 patients undergoing TACE was $9.8 \%$, CIN being defined as an abrupt increase of $\geq 50 \%$ over the baseline, or an absolute increase of $\geq 0.3 \mathrm{mg} / \mathrm{dl}$, in the serum creatinine level [14].

Patients reported to be at increased risk of CIN are those with renal impairment, including a low baseline eGFR, DM, and volume of CM, particularly when in combination. In such patients, the incidence of CIN was significantly higher, i.e. within the range $12 \%$ - 50\% [16]-[18]. However, our study did not show such a tendency; there was no significant correlation between the incidence of CIN and the presence of renal impairment (eGFR $<60 \mathrm{~mL} / \mathrm{min}$ ), DM, and the volume of CM. Pre- and post-fluid therapy may have been effective.

In addition, the Child-Pugh score, which represents liver function, was a specific and important risk factor for CIN in patients undergoing TACE. This result is consistent with other studies indicating that the severity of liver function was correlated with the occurrence of CIN [19]-[21]. Patients with HCC frequently have advanced LC. Advanced LC is characterized by peripheral vasodilatation associated with decreased renal perfusion due to the activation of intrinsic vasoconstrictor systems, such as the rennin-angiotensin axis [6] [7]. Administration of CM to these patients may aggravate intrarenal vasoconstriction and result in nephropathy more frequently. Therefore, since liver function is aggravated in patients with HCC, the incidence of nephropathy caused by CM would likely increase. In the present study, Child-Pugh class B or C was significantly associated with the development of CIN.

Serum albumin is the most abundant serum protein, being responsible for $70 \%$ of the osmotic pressure [22]. Although serum albumin has several functions in the body, the most important is maintenance of osmotic pressure in the vascular system. In addition, it has antioxidant properties [23]. Serum albumin has a preventive role against CIN through vascular expansion and anti-oxidant functions [24]. However, the mechanism responsible for the association between nephropathy and low serum albumin is not clearly understood. A low albumin level is assumed to play a role in the incidence of CIN through renal tubule cytotoxicity resulting from free radicals.

In the present study, multivariate analysis demonstrated that a low hemoglobin value was associated with the development of CIN. This is the first study to have found such an association. Only two previous studies have investigated the relationship between CIN and anemia [25] [26]. Nikolski et al. [25] evaluated 942 patients undergoing percutaneous coronary intervention and found that there was a significant tendency for the incidence of CIN to increase as the baseline hematocrit value decreased in patients with lower baseline eGFR levels. The other study of contrast MDCT found that CIN occurred in $7.8 \%$ of anemic patients, compared with $2.8 \%$ of non-anemic patients. Patients with renal insufficiency and anemia tended to have a significantly higher incidence of CIN ( $P=0.027)$ [26]. The possible mechanisms underlying the association between anemia and higher rates of CIN are still being debated. Anemia is common among individuals with reduced kidney function, generally because of decreased production of erythropoietin. This is a consequence of CKD, and also worsens the progression of renal insufficiency. Anemia increases the prevalence of CKD as creatinine clearance decreases [26]-[28]. Anemia-induced deterioration of renal ischemia may be one plausible explanation for the higher inci- 
dence of CIN in patients with low values of hematocrit and hemoglobin.

The present study has few limitations. First, it focused on the data from a single center and was limited by the small sample size. Second, this study did not include long-term follow-up data to assess the long-term prognosis. The scientific value of our data and the clinical importance of CIN after TACE will need to be confirmed by a large prospective study.

\section{Conclusion}

CIN in patients with HCC undergoing TACE was closely associated with the severity of LC, low serum levels of albumin and hemoglobin. Effective preventive measures should be applied in patients with HCC and high-risk patients who are undergoing TACE. The clinical significance of CIN should be further investigated in a large prospective study.

\section{References}

[1] Llovet, J.M., Real, M.I., Montaña, X., Planas, R., Coll, S., et al. (2002) Arterial Embolisation or Chemoembolisation versus Symptomatic Treatment in Patients with Unresectable Hepatocellular Carcinoma: A Randomised Controlled Trial. Lancet, 359, 1734-1739. http://dx.doi.org/10.1016/S0140-6736(02)08649-X

[2] Llovet, J.M., Burroughs, A. and Bruix, J. (2003) Hepatocellular Carcinoma. Lancet, 362, 1907-1917. http://dx.doi.org/10.1016/S0140-6736(03)14964-1

[3] Lopez, P.M., Villanueva, A. and Llovet, J.M. (2006) Systematic Review: Evidence-Based Management of Hepatocellular Carcinoma-An Updated Analysis of Randomized Controlled Trials. Alimentary Pharmacology \& Therapeutics, 23, 1535-1547. http://dx.doi.org/10.1111/j.1365-2036.2006.02932.x

[4] Lo, C.M., Ngan, H., Tso, W.K., Liu, C.L., Lam, C.M., et al. (2002) Randomized Controlled Trial of Transarterial Lipiodol Chemoembolization for Unresectable Hepatocellular Carcinoma. Hepatology, 35, 1164-1171. http://dx.doi.org/10.1053/jhep.2002.33156

[5] Ikeda, M., Maeda, S., Ashihara, H., Nagahama, H., Tanaka, M., et al. (2010) Transcatheter Arterial Infusion Chemotherapy with Cisplatin-Lipiodol Suspension in Patients with Hepatocellular Carcinoma. Journal of Gastroenterology, 45, 60-67. http://dx.doi.org/10.1007/s00535-009-0109-8

[6] Cárdenas, A., Ginès, P., Uriz, J., Bessa, X., Salmerón, J.M., et al. (2001) Renal Failure after Upper Gastrointestinal Bleeding in Cirrhosis: Incidence, Clinical Course, Predictive Factors, and Short-Term Prognosis. Hepatology, 34, 671676. http://dx.doi.org/10.1053/jhep.2001.27830

[7] Moreau, R. and Lebrec, D. (2003) Acute Renal Failure in Patients with Cirrhosis: Perspectives in the Age of MELD. Hepatology, 37, 233-243. http://dx.doi.org/10.1053/jhep.2003.50084

[8] Hou, S.H., Bushinsky, D.A., Wish, J.B., Cohen, J.J. and Harrington, J.T. (1983) Hospital-Acquired Renal Insufficiency: A Prospective Study. American Journal of Medicine, 74, 243-248. http://dx.doi.org/10.1016/0002-9343(83)90618-6

[9] Rihal, C.S., Textor, S.C., Grill, D.E., Berger, P.B., Ting, H.H., et al. (2002) Incidence and Prognostic Importance of Acute Renal Failure after Percutaneous Coronary Intervention. Circulation, 105, 2259-2264. http://dx.doi.org/10.1161/01.CIR.0000016043.87291.33

[10] Parfrey, P.S., Griffiths, S.M., Barrett, B.J., Paul, M.D., Genge, M., et al. (1989) Contrast Material-Induced Renal Failure in Patients with Diabetes Mellitus, Renal Insufficiency, or Both. A Prospective Controlled Study. New England Journal of Medicine, 320, 143-149. http://dx.doi.org/10.1056/NEJM198901193200303

[11] Rich, M.W. and Crecelius, C.A. (1990) Incidence, Risk Factors, and Clinical Course of Acute Renal Insufficiency after Cardiac Catheterization in Patients 70 Years of Age or Older. A Prospective Study. Archives of Internal Medicine, 150, 1237-1242. http://dx.doi.org/10.1001/archinte.1990.00390180067011

[12] Rudnick, M.R., Goldfarb, S., Wexler, L., Ludbrook, P.A., Murphy, M.J., et al. (1995) Nephrotoxicity of Ionic and Nonionic Contrast Media in 1196 Patients: A Randomized Trial. The Iohexol Cooperative Study. Kidney International, 47, 254-261. http://dx.doi.org/10.1038/ki.1995.32

[13] Huo, T.I., Wu, J.C., Huang, Y.H., Chiang, J.H., Lee, P.C., et al. (2004) Acute Renal Failure after Transarterial Chemoembolization for Hepatocellular Carcinoma: A Retrospective Study of the Incidence, Risk Factors, Clinical Course and Long-Term Outcome. Alimentary Pharmacology \& Therapeutics, 19, 999-1007. http://dx.doi.org/10.1111/j.1365-2036.2004.01936.x

[14] Park, J., Chung, H.C., Lee, J.S., Lee, B.M., Kim, D.M., et al. (2008) Acute Kidney Injury after Transarterial Chemoembolization for Hepatocellular Carcinoma: A Retrospective Analysis. Blood Purification, 26, 454-459. http://dx.doi.org/10.1159/000157322 
[15] Cho, H.S., Seo, J.W., Kang, Y., Bae, E.J., Kim, H.J., et al. (2011) Incidence and Risk Factors for Radiocontrast-Induced Nephropathy in Patients with Hepatocellular Carcinoma Undergoing Transcatheter Arterial Chemoembolization. Clinical and Experimental Nephrology, 15, 714-719. http://dx.doi.org/10.1007/s10157-011-0470-9

[16] Aspelin, P., Aubry, P., Fransson, S.G., Strasser, R., Willenbrock, R., et al. (2003) Nephrotoxic Effects in High-Risk Patients Undergoing Angiography. New England Journal of Medicine, 348, 491-499. http://dx.doi.org/10.1056/NEJMoa021833

[17] Goldenberg, I. and Matetzky, S. (2005) Nephropathy Induced by Contrast Media: Pathogenesis, Risk Factors and Preventive Strategies. Canadian Medical Association Journal, 172, 1461-1471. http://dx.doi.org/10.1503/cmaj.1040847

[18] Nyman, U., Almén, T., Jacobsson, B. and Aspelin, P. (2012) Are Intravenous Injections of Contrast Media Really Less Nephrotoxic than Intra-Arterial Injections? European Radiolog, 22, 1366-1371. http://dx.doi.org/10.1007/s00330-011-2371-4

[19] Moreau, R., Gaudin, C., Hadengue, A., Braillon, A., Roulot, D., et al. (1993) Renal Hemodynamics in Patients with Cirrhosis: Relationship with Ascites and Liver Failure. Nephron, 65, 359-363. http://dx.doi.org/10.1159/000187513

[20] Eckardt, K.U. (1999) Renal Failure in Liver Disease. Intensive Care Medicine, 25, 5-14. http://dx.doi.org/10.1007/s001340050780

[21] Hampel, H., Bynum, G.D., Zamora, E. and El-Serag, H.B. (2001) Risk Factors for the Development of Renal Dysfunction in Hospitalized Patients with Cirrhosis. American Journal of Gastroenterology, 96, 2206-2210. http://dx.doi.org/10.1111/j.1572-0241.2001.03958.x

[22] Farrugia, A. (2010) Albumin Usage in Clinical Medicine: Tradition or Therapeutic? Transfusion Medicine Reviews, 24, 53-63. http://dx.doi.org/10.1016/j.tmrv.2009.09.005

[23] Nicholson, J.P., Wolmarans, M.R. and Park, G.R. (2000) The Role of Albumin in Critical Illness. British Journal of Anaesthesia, 85, 599-610. http://dx.doi.org/10.1093/bja/85.4.599

[24] Song, J.S., Kim, S.I., Kim, W., Park, D.W., Kwak, H.J., et al. (2013) Incidence and Risk Factors of Contrast-Induced Nephropathy after Bronchial Arteriography or Bronchial Artery Embolization. Tuberculosis and Respiratory Diseases, 74, 163-168. http://dx.doi.org/10.4046/trd.2013.74.4.163

[25] Nikolsky, E., Mehran, R., Lasic, Z., Mintz, G.S. and Lansky, A.J. (2005) Low Hematocrit Predicts Contrast-Induced Nephropathy after Percutaneous Coronary Interventions. Kidney International, 67, 706-713. http://dx.doi.org/10.1111/j.1523-1755.2005.67131.x

[26] Murakami, R., Kumita, S., Hayashi, H., Sugizaki, K., Okazaki, E., et al. (2013) Anemia and the Risk of Contrast-Induced Nephropathy in Patients with Renal Insufficiency Undergoing Contrast-Enhanced MDCT. European Journal of Radiology, 82, e521-e524. http://dx.doi.org/10.1016/j.ejrad.2013.06.004

[27] Hsu, C.Y., Bates, D.W., Kuperman, G.J. and Curhan, G.C. (2001) Relationship between Hematocrit and Renal Function in Men and Women. Kidney International, 59, 725-731. http://dx.doi.org/10.1046/j.1523-1755.2001.059002725.X

[28] Strauss, M.J., Port, F.K., Somen, C. and Wolfe, R.A. (1993) An Estimate of the Size of the US Predialysis Population with Renal Insufficiency and Anemia. American Journal of Kidney Diseases, 21, 264-269. http://dx.doi.org/10.1016/S0272-6386(12)80744-X

\section{Submit or recommend next manuscript to SCIRP and we will provide best service for you:}

Accepting pre-submission inquiries through Email, Facebook, LinkedIn, Twitter, etc.

A wide selection of journals (inclusive of 9 subjects, more than 200 journals)

Providing 24-hour high-quality service

User-friendly online submission system

Fair and swift peer-review system

Efficient typesetting and proofreading procedure

Display of the result of downloads and visits, as well as the number of cited articles

Maximum dissemination of your research work

Submit your manuscript at: http://papersubmission.scirp.org/

Or contact ojrad@scirp.org 